\title{
Cortical tibial osteoperiosteal flap technique to achieve bony bridge in transtibial amputation: experience in nine adult patients
}

\author{
Mauricio Leal Mongon • Felipe Alberto Piva • \\ Sylvio Mistro Neto $\cdot$ Jose Andre Carvalho . \\ William Dias Belangero $\cdot$ Bruno Livani
}

Received: 26 July 2012/Accepted: 7 January 2013/Published online: 31 January 2013

(C) The Author(s) 2013. This article is published with open access at Springerlink.com

\begin{abstract}
Amputation, especially of the lower limbs, is a surgical procedure that gives excellent results when conducted under the appropriate conditions. In 1949 Ertl developed a technique for transtibial osteomyoplastic amputation which restored the intraosseous pressure through canal obliteration and expanded the area of terminal support through a bony bridge between the fibula and distal tibia. The aim of this study was to investigate the effectiveness of a modification of the original Ertl's technique in which a cortical osteoperiosteal flap created from the tibia is used to form a bony bridge during transtibial amputation in adults. Nine patients underwent leg amputations with the cortical tibial osteoperiosteal flap technique for reconstruction of the stump. The average duration of follow-up was 30.8 (range, 18-41) months. The post-surgery examination included a clinical examination and radiography. A 6-min walk test (Enright in Respir Care 48(8):783-785, 2003) was performed in the 32 nd week after amputation. At 24th week post-surgery, all patients had stumps that were painless and able to bear full weight through the end. The creation of a cortical osteoperiosteal flap from the tibia to the fibula during transtibial amputation is a safe and effective technique that provides a strong
\end{abstract}

M. L. Mongon ( $\square)$

Orthopedics and Traumatology Department, Hospital Estadual de Sumaré, UNICAMP, Rua Jose Augusto Silva 761 apto 31B, Campinas, Sao Paulo zip 13087-570, Brazil

e-mail: mauriciomongon@gmail.com

F. A. Piva - S. Mistro Neto - W. D. Belangero - B. Livani Orthopedics and Traumatology Department, State University of Campinas (UNICAMP), Campinas, Sao Paulo, Brazil

J. A. Carvalho

Physiotherapy Department, Instituto de Prótese e Órtese (IPO), Campinas, Sao Paulo, Brazil and painless terminal weight-bearing stump. This constitutes a useful option for young patients, athletes, and patients with high physical demands.

Keywords Amputation - Surgical technique - Tibia . Fibula · Flap

\section{Background}

Amputation, especially of the lower limbs, can give excellent results when used for correct indications [1]. Despite modern reconstruction techniques and replantation, the preservation of a severely traumatised lower limb or a limb that is affected by painful chronic osteomyelitis usually yields poorer functional results than amputation and prosthetic use [2]. Transtibial amputations result in excellent functional outcomes [3]. In 1949 Ertl developed a technique for transtibial osteomyoplastic amputation which restored the intraosseous pressure through canal obliteration and expanded the area of terminal support by creating a bony bridge between the fibula and distal tibia [4]. The original technique involved the preparation of a periosteum cylinder that was extracted from the tibia with attached bone fragments, which promoted tibiofibular synostosis at the distal extremity of the amputation stump. A major problem with this technique was that it is not always possible to achieve bony bridge formation [5]. Subsequently, variations of the bony bridge have been described $[6,7]$.

The aim of the present study was to describe a cortical tibial osteoperiosteal flap technique that generates a bony bridge during transtibial amputation of adults. In essence, this is a modification of the original technique described by Ertl. 


\section{Patients and method}

\section{Patients}

Between December 2008 and November 2010, nine patients underwent leg amputations with the cortical tibial osteoperiosteal flap technique for reconstruction of the stump. The pre-operative characteristics of the patients are listed in Table 1. The study sample was adult patients who had traumatic and osteomyelitic reasons for amputation. Those under the age of 18 years or with an insufficient tibia length to allow creation of the osteoperiosteal flap (i.e. the same contraindication as that for the original Ertl's technique) were excluded [8]. None of the selected patients had a systemic comorbidity (e.g. hypertension, diabetes, chronic vascular insufficiency), but three patients were smokers.

There were eight men and one woman (mean age, 30.5 years; range, 18-51 years). Six patients underwent amputation on the right side and three on the left side. All the amputations were unilateral. Seven patients presented with Gustillo \& Anderson IIIC open fractures [9, 10], and two patients had chronic painful osteomyelitis of the ankle and hind foot.

The average duration of follow-up was 30.8 (range, 18-41) months. The post-surgery examination included a clinical examination and radiography. A 6-min walk test [11] was performed in the 32nd week after amputation.

This study was carried out with the approval of an Ethics Committee. All patients provided informed written consent in accordance with the World Medical Association Declaration of Helsinki.

\section{Operative technique}

A transtibial amputation using the cortical tibial osteoperiosteal flap technique to create a bony bridge must be performed as distally as possible; the desired level is the osseous equivalent of the muscle-tendon transition of the gastrocnemius muscle (as in the original Ertl's technique).
All patients received antibiotic prophylaxis (cephalosporin $2 \mathrm{~g}$, administered intravenously within $30 \mathrm{~min}$ of the start of the procedure). The surgical procedure begins with two $8-\mathrm{cm}$ longitudinal incisions, one anterolateral and the other posteromedial, starting $2.5 \mathrm{~cm}$ above the level proposed for the tibial osteotomy. Distally, these incisions are connected by a circular incision. The two flaps so formed are elevated, keeping the deep fascia and muscular aponeurosis intact. A vertical incision is then made in the deep fascia, just lateral to the tibial crest. At this point, extreme care must be taken to avoid damage to the periosteum. Another vertical incision is made through the deep fascia, in alignment with the fibula. All of the anterior and lateral compartment muscles are removed. Up to this point, both the bones and the interosseous membrane are intact.

The fibula is sectioned at the final level planned for the tibia while preserving the interosseous membrane. The tibia is sectioned about $8 \mathrm{~cm}$ below the fibula, and the amputated distal extremity is removed (Fig. 1a).

The main neurovascular bundle is isolated, and the artery and veins clamped separately; the nerves are sectioned after mild traction to ensure that they will retract proximally as in the original technique of Ertl.

At the level of the definitive tibial division, a longitudinal osteotomy of the fibular half of the tibia is made and the fibula half removed; the medial half of the tibia remains intact with attached periosteum (Fig. 1b, c). The medial half of the distal tibia is divided into segments while preserving the periosteal layer such that a periosteum-supported strut graft made of these segments is created (Fig. 2a) to allow the osteoperiosteal flap to be flipped to cover both bones. This will eventually connect the tibia to the fibula (future bridge) distally (Fig. 2b). A 3.5-mm screw fixes the distal part of the pedicled osteoperiosteal flap to the distal fibula (Fig. 3a).

When the osteoperiosteal flap is complete, a cushion must be prepared from the two muscle flaps, the aponeurosis, and the remaining intact deep fascia. These must be sculpted properly so as to allow them to be sutured together under
Table 1 Pre-operative patients data

\begin{tabular}{llllll}
\hline $\begin{array}{l}\text { Patient } \\
\text { number }\end{array}$ & $\begin{array}{l}\text { Age at amputation } \\
\text { (years) }\end{array}$ & Gender & Aetiology & Side & Smoker \\
\hline 1 & 19 & Male & Trauma Gustilo IIIC & Right & No \\
2 & 46 & Male & Chronic Osteomyelitis & Left & Yes \\
3 & 27 & Male & Trauma Gustilo IIIC & Right & No \\
4 & 29 & Male & Trauma Gustilo IIIC & Right & No \\
5 & 35 & Male & Trauma Gustilo IIIC & Right & Yes \\
6 & 19 & Female & Trauma Gustilo IIIC & Right & No \\
7 & 31 & Male & Trauma Gustilo IIIC & Right & No \\
8 & 18 & Male & Trauma Gustilo IIIC & Left & No \\
9 & 51 & Male & Chronic Osteomyelitis & Left & Yes \\
\hline
\end{tabular}



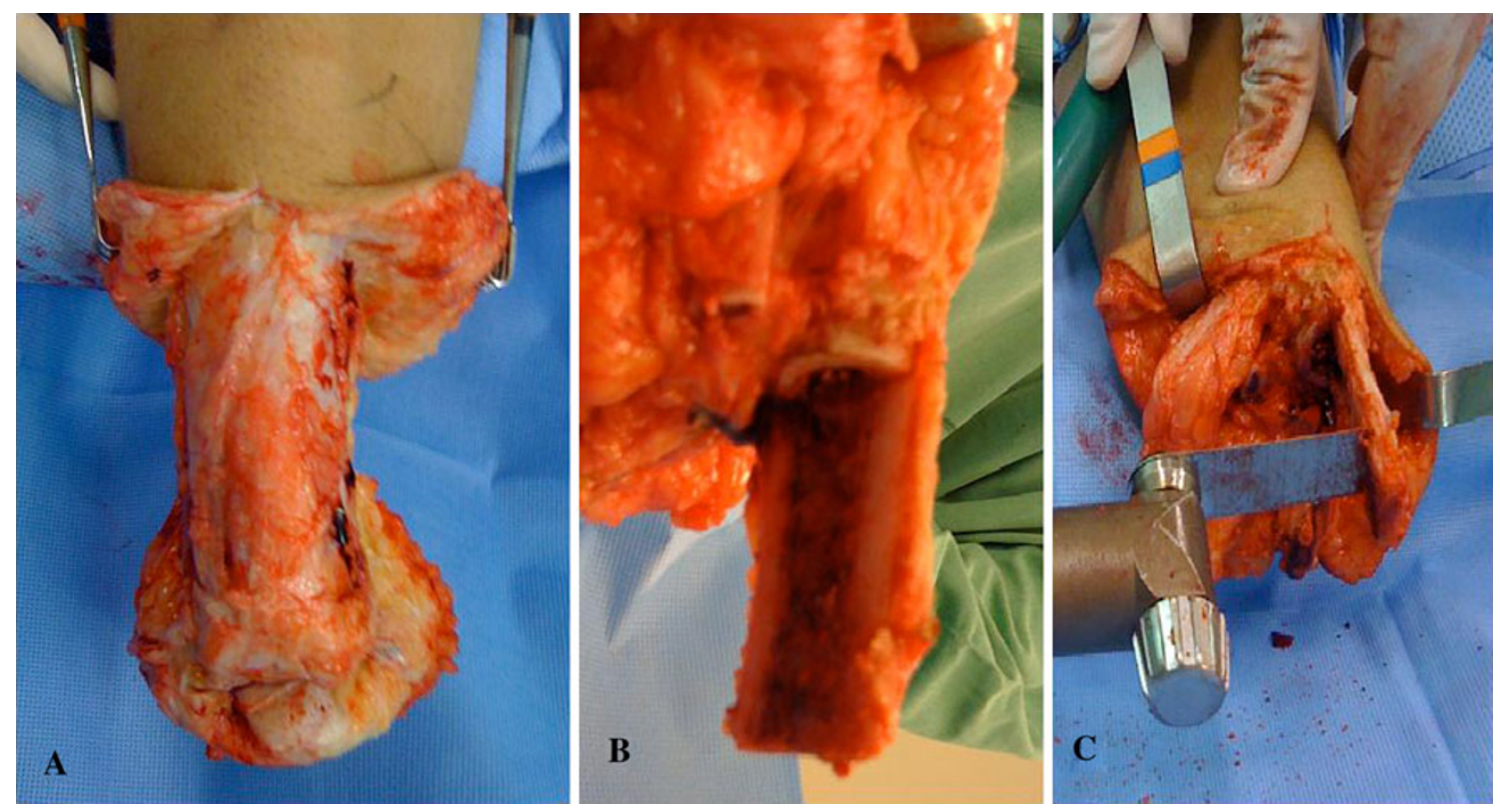

Fig. 1 a The amputated distal extremity is removed; b, $\mathbf{c}$ an longitudinal ostectomy of the fibular half of the tibia is made
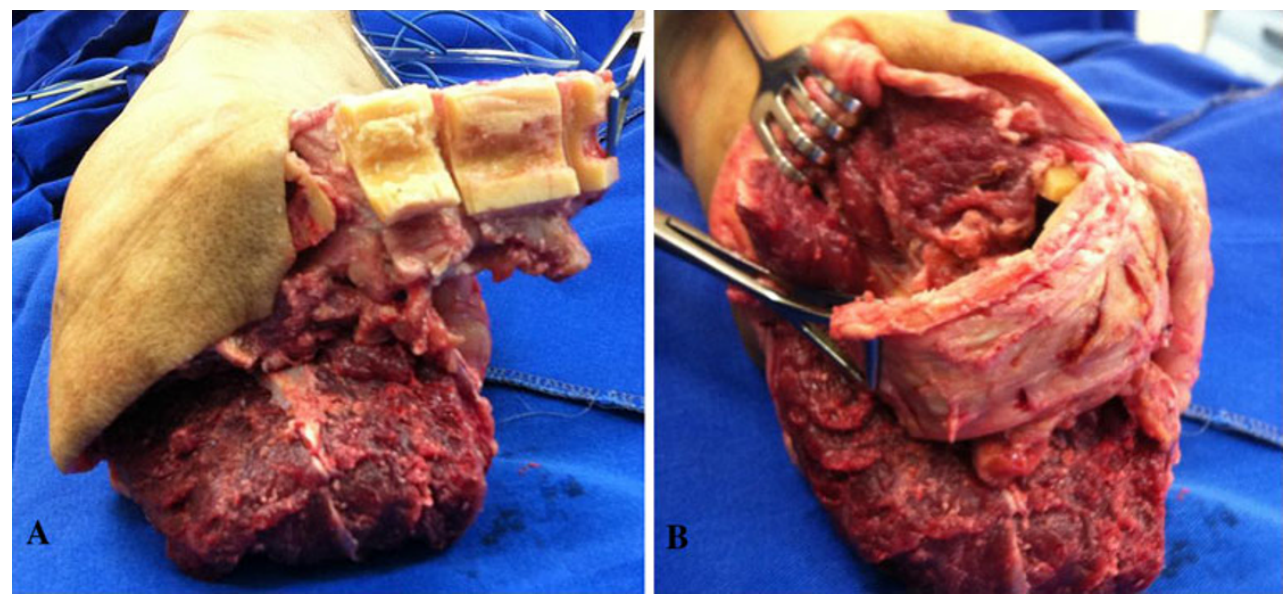

Fig. 2 a Tibial segmental ostectomy is performed; $\mathbf{b}$ osteoperiosteal flap is flipped covering both bones

mild tension. As described for the original Ertl's technique, the deep posterior compartment musculature should be resected at the same level as the tibial osteotomy, leaving only the gastrocnemius muscle as a posterior muscular flap. For the tibia, the prominence formed by its crest must be sculpted with round corners without osseous prominences.

The deep musculature enlarges the stump distal volume while the soleus muscle has intramural veins which may contribute to local haematoma formation. At this point, drains should be inserted in the bone and muscular plane. Both long flaps of skin are then cut and sutured under mild tension (Fig. 3b).

The skin suture line is positioned almost perpendicular to the muscle suture line; this helps prevent the formation of undesirable adherent scars among the planes. The surgical dressing used is the same as that recommended for a conventional amputation, that is, an elastic compression dressing that consists of orthopaedic cotton and an elastic bandage. Early knee motion is encouraged.

\section{Results}

The intraoperative procedure had no complications. There were no wound infections, and the incisions healed without complications. The stitches were removed at 3 or 4 weeks post-operatively.

A below-knee prosthesis was adapted to each patient at 7 (range, 6-8) weeks post-operatively. There was no need for stump revision during the entire follow-up period. 
Fig. 3 a X-ray showing a

3.5-mm screw fixing the distal pedicled strut graft

osteoperiosteal flap to the distal

fibula; b final stump

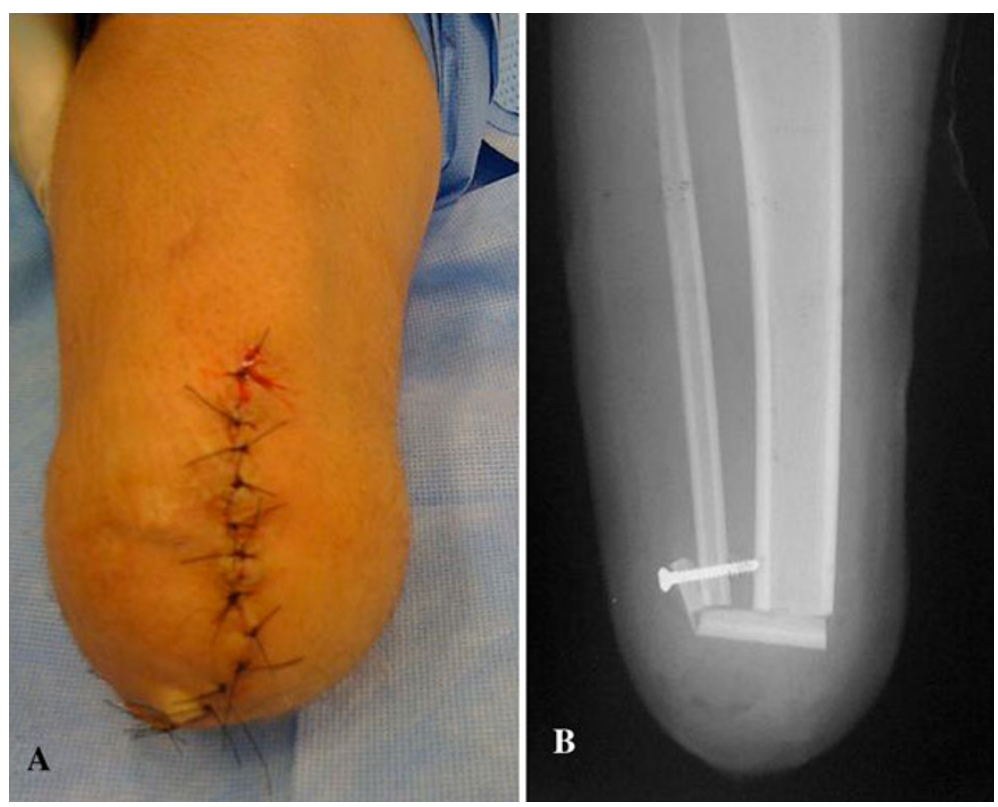

Fig. 4 a Patient number 3 with prosthesis; b final bony bridge

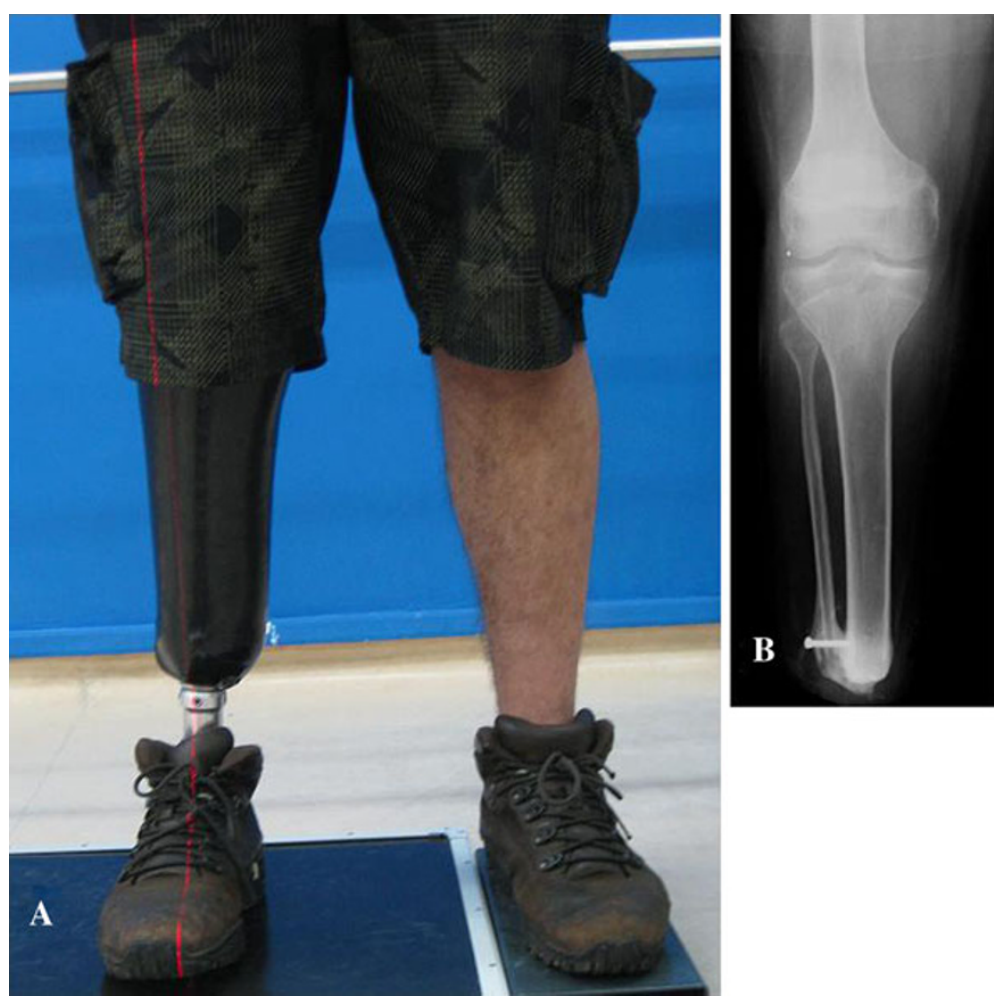

The patients were clinically and radiographically evaluated every 2 weeks. The patients' stumps were painless and capable of end-bearing weight at an average of 16 weeks post-surgery (range 15-17). Radiographically, all nine patients formed complete bony bridges at an average period of 16 weeks (range, 12-20). The 6-min walk test [11] produced an average result of $312 \mathrm{~m}$ (range, 280-340). Each patient was fitted with a prosthesis and subsequently reported a satisfactory quality of life (Fig. 4a, b). Table 2 lists the post-operative information for all the patients.

\section{Discussion}

In general, the quality of life of a lower-limb amputee with a functional stump is similar to that of an average person 
Table 2 Post-operative patients data

\begin{tabular}{lllll}
\hline $\begin{array}{l}\text { Patient } \\
\text { number }\end{array}$ & $\begin{array}{l}\text { Follow-up } \\
\text { (months) }\end{array}$ & $\begin{array}{l}\text { Bridge } \\
\text { formed } \\
\text { (weeks) }\end{array}$ & $\begin{array}{l}\text { Time to } \\
\text { prosthetisation } \\
\text { (weeks) }\end{array}$ & $\begin{array}{l}\text { Terminal } \\
\text { weight } \\
\text { bearing }\end{array}$ \\
\hline 1 & 41 & 14 & 7 & Yes \\
2 & 41 & 12 & 7 & Yes \\
3 & 35 & 18 & 8 & Yes \\
4 & 35 & 16 & 7 & Yes \\
5 & 31 & 18 & 8 & Yes \\
6 & 27 & 16 & 6 & Yes \\
7 & 26 & 16 & 7 & Yes \\
8 & 24 & 18 & 6 & Yes \\
9 & 18 & 16 & 8 & Yes \\
\hline
\end{tabular}

[12]. The sooner the patient returns to a daily routine, the greater is the chance of socio-economic re-adaptation [13]. Therefore, a technically well-constructed stump must be the primary objective of the orthopaedic surgeon.

In 1949, Ertl described an amputation technique that employed a bony bridge which, at least, in theory addressed all of the drawbacks of a conventional transtibial amputation [4]. This procedure closes the medullary canal with cortical bone, thereby restoring the intraosseous pressure, blood flow, and vascularisation [14]. The resulting bony bridge increases the terminal area of the stump, makes it more stable, and avoids posteromedial migration of the fibula and consequent funnelling. A larger stump base distributes the weight over a wider area, thereby reducing the pressure [4].

The cortical osteoperiosteal flap, which is a modification of the Ertl's bony bridge technique, has the advantage of a vascularised flap made of large strut grafts. A larger support area allows for wider distribution of the pressure which reduces the likelihood of pain and increases the weight-bearing ability of the terminal stump. This is particularly important for meeting the greater functional demands of certain patients such as young people, athletes, military personnel, and professionals who exert high levels of physical effort [15].

A drawback of all bony bridge techniques is that the initial level of the lesion cannot lie very proximal to the tibia, as this would prevent the construction of an osteoperiosteal flap of appropriate length. This means that the derivation of a bony bridge is impossible in oncological cases that require a wide surgical margin, as well as in many cases of trauma. In the cases presented here, the amputations were performed on patients who had experienced trauma to the lower limbs requiring early amputation or on patients who required amputation following the development of painful chronic osteomyelitis.

Primary wound closure performed within the zone of injury is a significant predictor of subsequent wound problems, regardless of the amputation technique used [16]. In this series of patients, all the amputations were for trauma and chronic infection and, for safety reasons and to reduce the risk of secondary wound complications
Fig. 5 a Patient number 1 with terminal full weight bearing; b right stump terminal full weight bearing. c Total weight of the patient
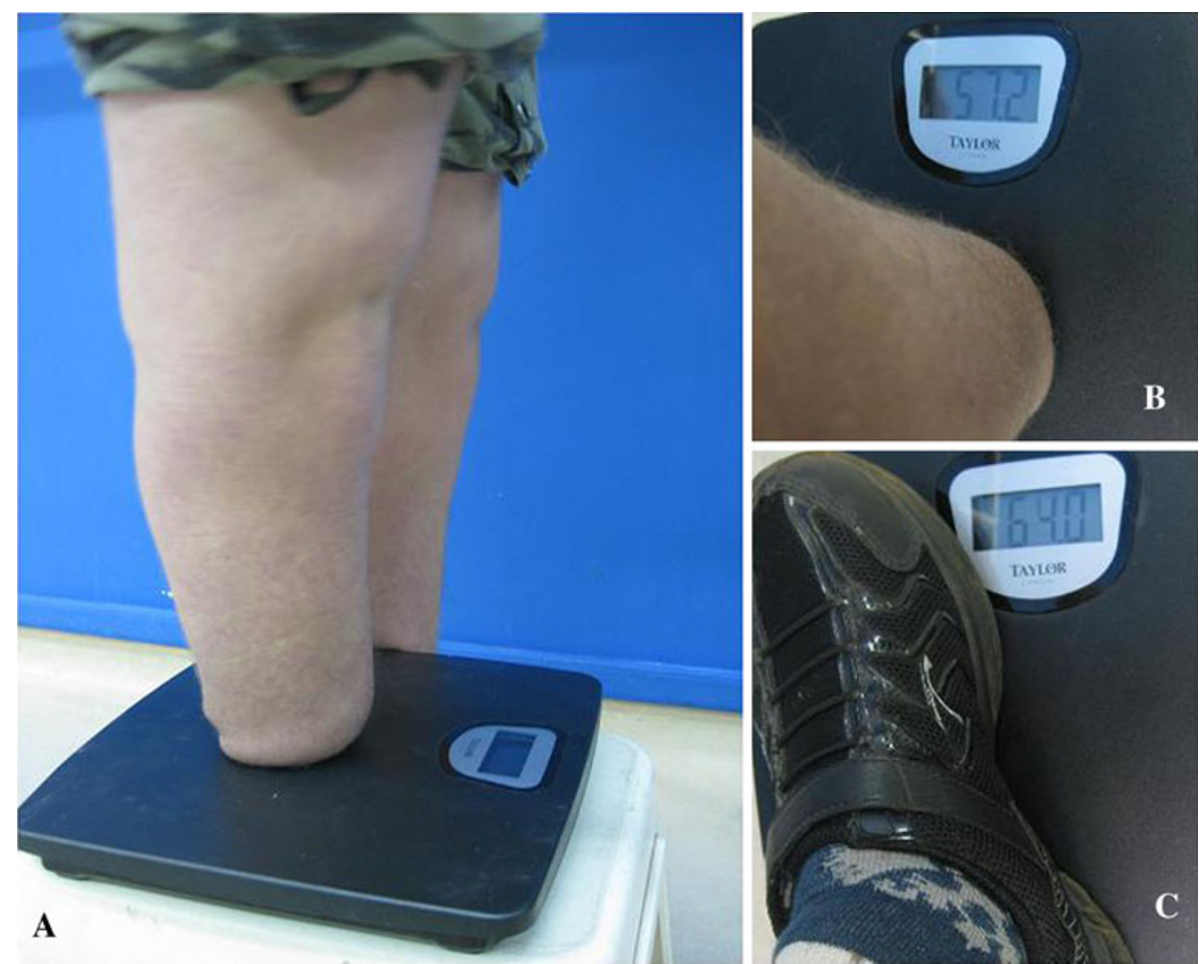
(e.g. dehiscence and stump infection), were left open with sterile dressings for $48 \mathrm{~h}$ using negative-pressure wound therapy; thereafter, a second examination was performed, at which point the osteoperiosteal flap was constructed and the wound closed [16].

The intraoperative procedure had no problems or complications. In all patients the wounds healed without complications. A below-knee prosthesis was adapted to all patients, and there was no need for stump revision during the entire follow-up period. All bony bridges were ossified at an average of 16 weeks, similar to the Ertl's original technique [4]. At the 6-month post-operative followup, all patients were able to bear full weight terminally (Fig. 5a-c).

The 6-min walk test is an inexpensive, safe, and easy-toapply test that can imply level of function with activities of the daily living. It is a way to assess the patient's functional capacity, monitor effectiveness of a treatment, and establish prognosis, as well as having good correlation with the maximum oxygen consumption [11]. The average result for patients with this technique was $312 \mathrm{~m}$.

\section{Conclusion}

The construction of a cortical tibial osteoperiosteal flap to achieve a bony bridge during transtibial amputation, which represents a modification of the original technique described by Ertl, is a safe and effective procedure that creates a strong, painless, terminal weight-bearing stump. This procedure could be a useful option for young patients, athletes, and patients with high physical demands.

Acknowledgments Authors would like to acknowledge Prof. Lourenco Sbragia Neto, FMRPUSP, Ribeirao Preto, SP, Brazil, and received funding from Sao Paulo State Research Foundation (FAPESP), Sao Paulo, Brazil (2009/02089-3).

Conflict of interest The authors report no conflict of interest.

Open Access This article is distributed under the terms of the Creative Commons Attribution License which permits any use, distribution, and reproduction in any medium, provided the original author(s) and the source are credited.

\section{References}

1. Livani B, de Castro GF, Filho JR, Belangero WD, Ramos TM, Mongon M (2011) Pedicled sensate composite calcaneal flap to achieve full weight-bearing surface in midshaft leg amputations: case report. J Reconstr Microsurg 27(1):63-66

2. Tekin L, Safaz Y, Göktepe AS, Yazýcýodlu K (2009) Comparison of quality of life and functionality in patients with traumatic unilateral below knee amputation and salvage surgery. Prosthet Orthot Int 33(1):17-24

3. Ebrahimzadeh MH, Hariri S (2009) Long-term outcomes of unilateral transtibial amputations. Mil Med 174(6):593-597

4. Mongon ML, Davitt M, Carvalho JA, Belangero WD, Livani B (2010) Transtibial amputation using the Ertl bony bridge technique. Eur Orthop Traumatol 1:21-24

5. Okamoto AM, Guarniero R, Coelho RF, Coelho FF, Pedrinelli A (2000) The use of bone bridges in transtibial amputations. Rev Hosp Clin Fac Med Sao Paulo 55(4):121-128

6. Pinto MA, Harris WW (2004) Fibular segment bone bridging in trans-tibial amputation. Prosthet Orthot Int 28(3):220-224

7. Ng VY, Berlet GC (2011) Improving function in transtibial amputation: the distal tibiofibular bone-bridge with Arthrex Tightrope fixation. Am J Orthop 40(4):E57-E60

8. Ertl J (1949) Uber amputationsstumpfe. Chirurg 20:218-224

9. Gustilo RB, Anderson JT (1976) Prevention of infection in the treatment of one thousand and twenty-five open fractures of long bones: retrospective and prospective analyses. J Bone Jt Surg Am 58(4):453-458

10. Gustilo RB, Mendoza RM, Williams DN (1984) Problems in the management of type III (severe) open fractures: a new classification of type III open fractures. J Trauma 24(8):742-746

11. Enright PL (2003) The six-minute walk test. Respir Care 48(8):783-785

12. Pinzur MS, Pinto MA, Saltzman M, Batista F, Gottschalk F, Juknelis D (2006) Health-related quality of life in patients with transtibial amputation and reconstruction with bone bridging of the distal tibia and fibula. Foot Ankle Int 27:907-912

13. Harness N, Pinzur MS (2001) Health related quality of life in patients with dysvascular transtibial amputation. Clin Orthop Relat Res 383:204-207

14. Pinzur MS, Beck J, Himes R, Callaci J (2008) Distal tibiofibular bone-bridging in transtibial amputation. J Bone Jt Surg Am 90(12):2682-2687

15. Legro MW, Reiber GD, Smith DG, del Aguila M, Larsen J, Boone D (1998) Prosthesis evaluation questionnaire for persons with lower limb amputations: assessing prosthesis-related quality of life. Arch Phys Med Rehabil 79:931-938

16. Gwinn DE, Keeling J, Froehner JW, McGuigan FX, Andersen R (2008) Perioperative differences between bone bridging and nonbone bridging transtibial amputations for wartime lower extremity trauma. Foot Ankle Int 29(8):787-793 